УДК 621.771

Ремез О. А. Огинский И. К. Кузьмина О. М.

\title{
МОДЕЛИРОВАНИЕ ПРОЦЕССА НЕПРЕРЫВНОЙ ПРОКАТКИ В КАЛИБРАХ СИСТЕМЫ «ОВАЛ-КРУГ»
}

Система калибров «овал-круг» применяется в сортопрокатном производстве в числе других вытяжных систем при прокатке углеродистых и специальных сталей. Технологические основы разработки названных систем были заложены достаточно давно, в основном для их создания были использованы экспериментальные методы. Теоретические методы появились и получили свое развитие несколько позже, и продолжают развиваться исследователями до настоящего времени [1-16 и др.]. Разработка технологии прокатки для различных групп сталей на непрерывных станах выполняется в отсутствии достаточно глубоких сведений о взаимосвязи высотной и поперечной деформаций в условиях переднего, заднего натяжения и совместного их действия. Недостаточно исследованным также является влияние систем вытяжных калибров на параметры прокатки в непрерывных станах.

Основные сведения о закономерностях изменения технологических параметров и их взаимосвязи при прокатке в калибрах были установлены в результате физического моделирования. Методы компьютерного моделирования, активно развивающиеся в последнее время, позволяют получить дополнительную информацию, однако они не являются достаточными для использования в практических целях. Не все программные средства являются хорошо адаптированными для практических задач. Некоторые программные пакеты по своему замыслу являются специализированными для решения задач сортовой прокатки [17, 18], но и они не обладают достаточными возможностями. Недостаток апробированных решений вызывает необходимость развития и создания новых научных подходов и делает работы в этих направлениях актуальными.

Целью настоящей работы является развитие методов исследования кинематических параметров непрерывной сортовой прокатки с помощью компьютерного моделирования и определение на этой основе закономерностей изменения технологических параметров деформации заготовки в системе вытяжных калибров «овал-круг».

Исследование параметров прокатки в калибрах системы «овал-круг» проводилось с использованием конечно-элементной программы компьютерного моделирования процессов обработки металлов давлением FORGE 3D, разработанной компанией TRANSVALOR S. A. FORGE 3D. Программа компьютерного моделирования процессов обработки металлов давлением FORGE 3D использовалась при совместных научно-исследовательских работах между НМетАУ и Ченстаховским политехническим институтом (Польша, договор №M/133-2009 от 30 марта 2009 г.). Программа предназначена для моделирования технологических процессов обработки металлов давлением в достаточно широкой постановке относительно кинематики и условий трения металла и инструмента.

Расчет формоизменения, полей напряжений, степени деформации и температур основан на минимизации функционала вариационного принципа Лагранжа, сформулированного следующим образом:

$$
I=\int_{V}\left(\int_{0}^{\mathrm{H}} \mathrm{T} d \mathrm{H}\right) d V-\int_{V} F_{i} U_{i} d V-\int_{S} f_{i} U_{i} d S,
$$

где $T$ - интенсивность касательных напряжений;

$H$ - интенсивность скоростей деформации сдвига;

$F_{\mathrm{i}}, f_{\mathrm{i}}, U_{\mathrm{i}}-$ проекции векторов объемных сил, поверхностных нагрузок и скоростей течения, соответственно; 
$S$ - площадь поверхности контакта металла с валком;

$V$ - деформируемый объем.

В программе используются конечные элементы в виде тетраэдров с линейной аппроксимацией среднего напряжения и кусочно-линейной аппроксимацией скорости (по угловым узлам элемента и узлу в центре тяжести элемента).

Сопротивление деформации (напряжение текучести) деформируемого материала могут быть заданы на основе данных Хензеля-Шпиттеля [19].

B FORGE 3D доступно 6 моделей для описания трения между деформируемым объектом и инструментом, одной из них является вязкопластическая модель трения:

$$
\tau=-\alpha_{f} \cdot K \cdot\left|v_{s}\right|^{q-1} \cdot v_{s}
$$

где $\alpha_{f}-$ коэффициент трения, который зависит от нормальных напряжений на контакте;

$q$ - чувствительность к скорости скольжения;

$v_{\mathrm{s}}$ - разница касательных составляющих скоростей заготовки и инструмента.

Среди других: модель трения Треска, комбинированная модель закона Кулона и модели Треска, модель трения «Nocontact» (модель позволяет не учитывать контакт между инструментом и деформируемым объектом или между двумя деформируемыми объектами), модель трения Бернхардта и модель трения Ноймайера.

Основу тепловой части модели составляет уравнение теплопроводности, приведенное в общем виде:

$$
\frac{d t}{d \tau}=a\left(\frac{\partial^{2} t}{\partial x^{2}}+\frac{\partial^{2} t}{\partial y^{2}}\right)+q_{d e f}
$$

где $a$ - коэффициент температуропроводности;

$q_{d e f}$ - тепло, выделяемое при деформации.

Граничные условия при решении температурной задачи:

$$
-k \frac{\partial T}{\partial n}=h_{c}\left(T-T_{c}\right)+\varepsilon_{r} \times \sigma_{r}\left(T^{4}-T_{0}^{4}\right)
$$

где $n$ - вектор, ортогональный к поверхности;

$T_{0}$ - температура окружающей среды или инструмента;

$\varepsilon_{r}$ - степень черноты поверхности;

$\sigma_{r}$ - константа Больцмана;

$h_{c}$ - коэффициент теплопередачи.

Исследования проводились для стали 08X13 (химический состав регламентируется ГОСТ 5632-72). Эта сталь относится к числу тех, что обладают склонностью к повышенному уширению. Названная особенность изучена в недостаточной степени, и по этой причине возникают трудности при разработке режимов обжатий. Указанные стали содержатся в марочном сортаменте заводов, работающих со специальными марками, и представляют практический интерес.

Результаты моделирования (табл. 1-3) были предназначены, в частности, для использования в экспериментальных исследованиях. Индексы и символы «Б/н» относятся к прокатке без натяжения, «Н» - к прокатке с натяжением. Обозначения $\mathrm{b}_{1}$ и $\mathrm{F}_{1}-$ соответственно, ширина раската и площадь поперечного сечения после прокатки. Параметр $\mathrm{h}_{1}$ означает высоту раската после прокатки, численно он равен высоте раската по дну калибра, например, на рис. 2 эта величина составляет $\mathrm{h}_{1}=2 \mathrm{mм} ; \mathrm{V}_{0}$ - скорость раската на входе в очаг деформации, $\mathrm{V}_{1}$ - скорость прокатки.

Исходные данные и условия моделирования прокатки: скорость вращения валков 32 об/мин, используется заготовка круглого сечения диаметром 30,5 мм, диаметр валков по дну калибра - 194 мм.

Свойства деформируемых материалов представлены реологическими зависимостями, приведенными в работе [20], в графическом виде они отображены на рис. 1. 
Таблица 1

Результаты моделирования процесса прокатки по схеме «круг-овал» с задним натяжением

\begin{tabular}{|c|c|c|c|c|c|c|c|c|c|c|c|c|c|c|c|}
\hline \multirow{2}{*}{$\mathrm{h}_{1}, \mathrm{MM}$} & \multicolumn{3}{|c|}{$\mathrm{F}_{1}, \mathrm{MM}^{2}$} & \multicolumn{3}{|c|}{$\mathrm{b}_{1}, \mathrm{MM}$} & \multicolumn{2}{|c|}{$\Delta \mathrm{B}, \mathrm{MM}$} & \multicolumn{3}{|c|}{$\lambda$} & \multirow{2}{*}{$\mathrm{V0} / \mathrm{V} 0 \mathrm{H}$} & \multirow{2}{*}{$\mathrm{V}_{1 \mathrm{n}} / \mathrm{V}_{1}$} & \multirow{2}{*}{$\Delta \mathrm{b}_{\mathrm{n}} / \Delta \mathrm{b}$} & \multirow{2}{*}{$\lambda_{\mathrm{n}} / \lambda$} \\
\hline & 5 & $\mathrm{H}$ & $\Delta, \%$ & Б & $\mathrm{H}$ & $\Delta, \%$ & Б & $\mathrm{H}$ & Б & $\mathrm{H}$ & $\Delta, \%$ & & & & \\
\hline 16,71 & 549,17 & 539,96 & $-1,706$ & 37,42 & 36,64 & $-2,130$ & 6,92 & 6,14 & 1,327 & 1,349 & 1,677 & 1,025 & 0,997 & 0,887 & 1,017 \\
\hline 18,71 & 589,60 & 581,48 & $-1,397$ & 35,84 & 35,34 & $-1,420$ & 5,34 & 4,84 & 1,236 & 1,253 & 1,378 & 1,025 & 0,994 & 0,906 & 1,014 \\
\hline 20,31 & 616,76 & 608,92 & $-1,288$ & 34,67 & 34,18 & $-1,414$ & 4,17 & 3,68 & 1,181 & 1,197 & 1,271 & 1,025 & 0,995 & 0,884 & 1,013 \\
\hline 23,30 & 661,46 & 653,46 & $-1,224$ & 32,81 & 32,47 & $-1,055$ & 2,31 & 1,97 & 1,101 & 1,115 & 1,209 & 1,025 & 0,995 & 0,852 & 1,012 \\
\hline 24,14 & 672,09 & 665,51 & $-0,989$ & 32,39 & 32,08 & $-0,966$ & 1,89 & 1,58 & 1,084 & 1,095 & 0,979 & 1,025 & 0,993 & 0,836 & 1,010 \\
\hline 25,23 & 684,79 & 676,68 & $-1,198$ & 31,85 & 31,53 & $-1,017$ & 1,35 & 1,03 & 1,064 & 1,077 & 1,184 & 1,025 & 0,990 & 0,763 & 1,012 \\
\hline 26,43 & 698,41 & 690,84 & $-1,095$ & 31,37 & 31,10 & $-0,868$ & 0,87 & 0,60 & 1,043 & 1,055 & 1,084 & 1,025 & 0,987 & 0,690 & 1,011 \\
\hline 16,71 & 549,17 & 531,80 & $-3,266$ & 37,42 & 36,03 & $-3,866$ & 6,92 & 5,53 & 1,327 & 1,370 & 3,163 & 1,050 & 0,993 & 0,799 & 1,033 \\
\hline 18,71 & 589,60 & 572,62 & $-2,966$ & 35,84 & 34,79 & $-3,026$ & 5,34 & 4,29 & 1,236 & 1,272 & 2,881 & 1,050 & 0,990 & 0,803 & 1,030 \\
\hline 20,31 & 616,76 & 600,47 & $-2,713$ & 34,67 & 33,73 & $-2,781$ & 4,17 & 3,23 & 1,181 & 1,213 & 2,641 & 1,050 & 0,988 & 0,775 & 1,027 \\
\hline 23,30 & 661,46 & 644,36 & $-2,654$ & 32,81 & 32,04 & $-2,409$ & 2,31 & 1,54 & 1,101 & 1,131 & 2,586 & 1,050 & 0,986 & 0,666 & 1,027 \\
\hline 24,14 & 672,09 & 657,90 & $-2,157$ & 32,39 & 31,76 & $-1,980$ & 1,89 & 1,26 & 1,084 & 1,107 & 2,111 & 1,050 & 0,986 & 0,668 & 1,022 \\
\hline 25,23 & 684,79 & 671,65 & $-1,956$ & 31,85 & 31,33 & $-1,661$ & 1,35 & 0,83 & 1,064 & 1,085 & 1,919 & 1,050 & 0,975 & 0,616 & 1,020 \\
\hline 26,43 & 698,41 & 685,90 & $-1,823$ & 31,37 & 30,91 & $-1,493$ & 0,87 & 0,41 & 1,043 & 1,062 & 1,790 & 1,050 & 0,971 & 0,470 & 1,018 \\
\hline 16,71 & 549,17 & 525,02 & $-4,600$ & 37,42 & 35,68 & $-4,880$ & 6,92 & 5,18 & 1,327 & 1,388 & 4,398 & 1,075 & 0,986 & 0,749 & 1,046 \\
\hline 18,71 & 589,60 & 563,66 & $-4,602$ & 35,84 & 34,27 & $-4,601$ & 5,34 & 3,77 & 1,236 & 1,293 & 4,400 & 1,075 & 0,984 & 0,705 & 1,046 \\
\hline 20,31 & 616,76 & 599,78 & $-2,830$ & 34,67 & 33,66 & $-2,999$ & 4,17 & 3,16 & 1,181 & 1,215 & 2,752 & 1,075 & 0,984 & 0,758 & 1,028 \\
\hline 23,30 & 661,46 & 639,31 & $-3,464$ & 32,81 & 31,82 & $-3,098$ & 2,31 & 1,32 & 1,101 & 1,140 & 3,348 & 1,075 & 0,979 & 0,573 & 1,035 \\
\hline 24,14 & 672,09 & 649,53 & $-3,473$ & 32,39 & 31,39 & $-3,193$ & 1,89 & 0,89 & 1,084 & 1,122 & 3,357 & 1,075 & 0,965 & 0,470 & 1,035 \\
\hline 25,23 & 684,79 & 664,02 & $-3,127$ & 31,85 & 31,01 & $-2,709$ & 1,35 & 0,51 & 1,064 & 1,097 & 3,032 & 1,075 & 0,955 & 0,379 & 1,031 \\
\hline 26,43 & 698,41 & 683,12 & $-2,237$ & 31,37 & 30,80 & $-1,839$ & 0,87 & 0,30 & 1,043 & 1,067 & 2,188 & 1,075 & 0,958 & 0,349 & 1,022 \\
\hline 16,71 & 549,17 & 522,44 & $-5,116$ & 37,42 & 35,49 & $-5,461$ & 6,92 & 4,99 & 1,327 & 1,395 & 4,867 & 1,100 & 0,982 & 0,720 & 1,051 \\
\hline 18,71 & 589,60 & 560,73 & $-5,150$ & 35,84 & 34,10 & $-5,123$ & 5,34 & 3,60 & 1,236 & 1,299 & 4,898 & 1,100 & 0,975 & 0,673 & 1,051 \\
\hline 20,31 & 616,76 & 585,52 & $-5,335$ & 34,67 & 32,94 & $-5,234$ & 4,17 & 2,44 & 1,181 & 1,244 & 5,065 & 1,100 & 0,974 & 0,586 & 1,053 \\
\hline 23,30 & 661,46 & 634,31 & $-4,281$ & 32,81 & 31,57 & $-3,919$ & 2,31 & 1,07 & 1,101 & 1,149 & 4,105 & 1,100 & 0,961 & 0,464 & 1,043 \\
\hline 24,14 & 672,09 & 644,95 & $-4,208$ & 32,39 & 31,23 & $-3,714$ & 1,89 & 0,73 & 1,084 & 1,130 & 4,038 & 1,100 & 0,946 & 0,387 & 1,042 \\
\hline 25,23 & 684,79 & 660,16 & $-3,731$ & 31,85 & 30,85 & $-3,252$ & 1,35 & 0,35 & 1,064 & 1,104 & 3,597 & 1,100 & 0,936 & 0,259 & 1,037 \\
\hline 26,43 & 698,41 & 680,26 & $-2,668$ & 31,37 & 30,69 & $-2,232$ & 0,87 & 0,19 & 1,043 & 1,071 & 2,599 & 1,100 & 0,928 & 0,214 & 1,027 \\
\hline
\end{tabular}


Таблица 2

Результаты моделирования процесса прокатки по схеме «круг-овал» с передним натяжением

\begin{tabular}{|c|c|c|c|c|c|c|c|c|c|c|c|c|c|c|c|}
\hline \multirow{2}{*}{$\mathrm{h}_{1}, \mathrm{MM}$} & \multicolumn{3}{|c|}{$\mathrm{F}_{1}, \mathrm{MM}^{2}$} & \multicolumn{3}{|c|}{$\mathrm{b}_{1}, \mathrm{MM}$} & \multicolumn{2}{|c|}{$\Delta \mathrm{B}, \mathrm{MM}$} & \multicolumn{3}{|c|}{$\lambda$} & \multirow{2}{*}{$\mathrm{V}_{0} / \mathrm{V}_{0 \mathrm{H}}$} & \multirow{2}{*}{$\mathrm{V}_{1 \mathrm{H}} / \mathrm{V}_{1}$} & \multirow{2}{*}{$\Delta \mathrm{b}_{\mathrm{H}} / \Delta \mathrm{b}$} & \multirow{2}{*}{$\lambda_{\mathrm{H}} / \lambda$} \\
\hline & Б & $\mathrm{H}$ & $\Delta, \%$ & Б & $\mathrm{H}$ & $\Delta, \%$ & Б & $\mathrm{H}$ & Б & $\mathrm{H}$ & $\Delta, \%$ & & & & \\
\hline 16,71 & 549,17 & 543,10 & $-1,117$ & 37,42 & 37,04 & $-1,033$ & 6,92 & 6,54 & 1,327 & 1,342 & 1,104 & 0,991 & 1,025 & 0,945 & 1,011 \\
\hline 18,71 & 589,60 & 582,76 & $-1,174$ & 35,84 & 35,44 & $-1,138$ & 5,34 & 4,94 & 1,236 & 1,250 & 1,160 & 0,991 & 1,025 & 0,924 & 1,012 \\
\hline 20,31 & 616,76 & 610,13 & $-1,086$ & 34,67 & 34,30 & $-1,074$ & 4,17 & 3,80 & 1,181 & 1,194 & 1,075 & 994 & 1,025 &, 912 & 1,011 \\
\hline 23,30 & 661,46 & 655,87 & $-0,852$ & 32,81 & 32,60 & $-0,651$ & 2,31 & 2,10 & 1,101 & 1,111 & 0,845 & 0,986 & 1,025 & 0,908 & 1,009 \\
\hline 24,14 & 672,09 & 666,30 & $-0,869$ & 32,39 & 32,16 & $-0,708$ & 1,89 & 1,66 & 1,084 & 1,093 & 0,861 & 0,986 & 1,025 & 0,880 & 1,009 \\
\hline 25,23 & 684,79 & 680,79 & $-0,587$ & 31,85 & 31,69 & $-0,528$ & 1,35 & 1,19 & 1,064 & 1,070 & 0,584 & 0,977 & 1,025 & 0,876 & 1,006 \\
\hline 26,43 & 698,41 & 693,68 & $-0,681$ & 31,37 & 31,21 & $-0,502$ & 0,87 & 0,71 & 1,043 & 1,050 & 0,676 & 0,978 & 1,025 & 0,820 & 1,007 \\
\hline 16,71 & 549,17 & 538,10 & $-2,058$ & 37,42 & 36,59 & $-2,282$ & 6,92 & 6,09 & 1,327 & 1,354 & 2,016 & 70 & 1,050 & 79 & 1,021 \\
\hline 18,71 & 589,60 & 576,39 & $-2,293$ & 35,84 & 35,10 & $-2,127$ & 5,34 & 4,60 & 1,236 & 1,264 & 2,242 & 976 & 1,050 & 860 & 1,023 \\
\hline 20,31 & 616,76 & 604,27 & $-2,067$ & 34,67 & 34,02 & $-1,887$ & 4,17 & 3,52 & 1,181 & 1,206 & 2,025 & 0,972 & 1,050 & 0,846 & 1,021 \\
\hline 23,30 & 661,46 & 650,62 & $-1,665$ & 32,81 & 32,38 & $-1,317$ & 2,31 & 1,88 & 1,101 & 1,120 & 1,638 & 0,970 & 1,050 & 0,815 & 1,017 \\
\hline 24,14 & 672,09 & 663,04 & $-1,364$ & 32,39 & 32,00 & $-1,233$ & 1,89 & 1,50 & 1,084 & 1,099 & 1,346 & 966 & 1,050 & 792 & 1,014 \\
\hline 25,23 & 684,79 & 677,98 & $-1,004$ & 31,85 & 31,57 & $-0,896$ & 1,35 & 1,07 & 1,064 & 1,075 & 0,994 & 0,961 & 1,050 &, 791 & 1,010 \\
\hline 26,43 & 698,41 & 691,81 & $-0,954$ & 31,37 & 31,13 & $-0,786$ & 0,87 & 0,63 & 1,043 & 1,053 & 0,945 &, 958 & 1,050 & 0,719 & 1,010 \\
\hline 16,71 & 549,17 & 532,91 & $-3,051$ & 37,42 & 36,22 & $-3,322$ & 6,92 & 5,72 & 1,327 & 1,367 & 2,961 & 0,967 & 1,075 & 0,826 & 1,031 \\
\hline 18,71 & 589,60 & 570,52 & $-3,344$ & 35,84 & 34,78 & $-3,056$ & 5,34 & 4,28 & 1,236 & 1,277 & 3,236 & 0,972 & 1,075 & 0,801 & 1,033 \\
\hline 20,31 & 616,76 & 599,08 & $-2,952$ & 34,67 & 33,71 & $-2,832$ & 4,17 & 3,21 & 1,181 & 1,216 & 2,867 & 965 & 1,075 & 771 & 1,030 \\
\hline 23,30 & 661,46 & 646,67 & $-2,287$ & 32,81 & 32,20 & $-1,880$ & 2,31 & 1,70 & 1,101 & 1,127 & 2,236 & 0,953 & 1,075 & 0,738 & 1,023 \\
\hline 24,14 & 672,09 & 659,36 & $-1,930$ & 32,39 & 31,85 & $-1,700$ & 1,89 & 1,35 & 1,084 & 1,105 & 1,894 & 0,948 & 1,075 & 0,714 & 1,019 \\
\hline 25,23 & 684,79 & 674,47 & $-1,530$ & 31,85 & 31,46 & $-1,255$ & 1,35 & 0,96 & 1,064 & 1,080 & 1,507 & 0,944 & 1,075 & 0,708 & 1,015 \\
\hline 26,43 & 698,41 & 690,26 & $-1,180$ & 31,37 & 31,08 & & 0,87 & 0,58 & 1,043 & 1,056 & 1,166 & & 1,075 & & 1,012 \\
\hline 16,71 & 549,17 & 529,86 & $-3,644$ & 37,42 & 36,08 & $-3,727$ & 6,92 & 5,58 & 1,327 & 1,375 & 3,516 & 0,960 & 1,100 &, 806 & 1,036 \\
\hline 18,71 & 589,60 & 565,24 & $-4,311$ & 35,84 & 34,47 & $-3,974$ & 5,34 & 3,97 & 1,236 & 1,289 & 4,133 & 0,956 & 1,100 & 0,744 & 1,043 \\
\hline 20,31 & 616,76 & 594,06 & $-3,821$ & 34,67 & 33,48 & $-3,542$ & 4,17 & 2,98 & 1,181 & 1,226 & 3,681 & 0,951 & 1,100 & 0,715 & 1,038 \\
\hline 23,30 & 661,46 & 642,18 & $-3,002$ & 32,81 & 32,04 & $-2,389$ & 2,31 & 1,54 & 1,101 & 1,135 & 2,915 & 0,938 & 1,100 & 0,669 & 1,030 \\
\hline 24,14 & 672,09 & 655,63 & $-2,510$ & 32,39 & 31,71 & $-2,144$ & 1,89 & 1,21 & 1,084 & 1,111 & 2,448 & 0,938 & 1,100 & 0,641 & 1,025 \\
\hline 25,23 & 684,79 & 672,67 & $-1,801$ & 31,85 & 31,38 & $-1,525$ & 1,35 & 0,88 & 1,064 & 1,083 & 1,769 & 0,923 & 1,100 & 0,647 & 1,018 \\
\hline 26,43 & 698,41 & 689,41 & $-1,305$ & 31,37 & 31,03 & $-1,103$ & 0,87 & 0,53 & 1,043 & 1,057 & 1,288 & 0,920 & 1,100 & 0,607 & 1,013 \\
\hline
\end{tabular}


Таблица 3

Результаты моделирования процесса прокатки по схеме «круг-овал» с передним и задним натяжением

\begin{tabular}{|c|c|c|c|c|c|c|c|c|c|c|c|c|c|c|}
\hline \multirow{2}{*}{$\mathrm{h}_{1}, \mathrm{MM}$} & \multicolumn{3}{|c|}{$\mathrm{F}_{1}, \mathrm{MM}^{2}$} & \multicolumn{3}{|c|}{$\mathrm{b}_{1}, \mathrm{MM}$} & \multicolumn{2}{|l|}{$\Delta \mathrm{B}, \mathrm{MM}$} & \multicolumn{3}{|c|}{$\lambda$} & \multirow{2}{*}{$\begin{array}{l}\mathrm{V}_{0} / \mathrm{V}_{0 \mathrm{H}}= \\
=\mathrm{V}_{1 \mathrm{H}} / \mathrm{V}_{1}\end{array}$} & \multirow{2}{*}{$\Delta \mathrm{b}_{\mathrm{H}} / \Delta \mathrm{b}$} & \multirow{2}{*}{$\lambda_{\mathrm{H}} / \lambda$} \\
\hline & Б & $\mathrm{H}$ & $\Delta, \%$ & Б & $\mathrm{H}$ & $\Delta, \%$ & Б & $\mathrm{H}$ & Б & $\mathrm{H}$ & $\Delta, \%$ & & & \\
\hline 16,71 & 549,17 & 523,03 & $-4,997$ & 37,42 & 35,59 & $-5,148$ & 6,92 & 5,09 & 1,327 & 1,393 & 4,759 & 1,025 & 0,735 & 1,050 \\
\hline 18,71 & 589,60 & 562,64 & $-4,793$ & 35,84 & 34,17 & $-4,883$ & 5,34 & 3,67 & 1,236 & 1,295 & 4,574 & 1,025 & 0,688 & 1,048 \\
\hline 20,31 & 616,76 & 587,45 & $-4,989$ & 34,67 & 33,15 & $-4,571$ & 4,17 & 2,65 & 1,181 & 1,240 & 4,752 & 1,025 & 0,636 & 1,050 \\
\hline 23,30 & 661,46 & 630,64 & $-4,887$ & 32,81 & 31,44 & $-4,363$ & 2,31 & 0,94 & 1,101 & 1,155 & 4,659 & 1,025 & 0,406 & 1,049 \\
\hline 24,14 & 672,09 & 640,37 & $-4,953$ & 32,39 & 30,97 & $-4,604$ & 1,89 & 0,47 & 1,084 & 1,138 & 4,720 & 1,025 & 0,246 & 1,050 \\
\hline 25,23 & 684,79 & 649,08 & $-5,501$ & 31,85 & 30,42 & $-4,724$ & 1,35 & $-0,08$ & 1,064 & 1,122 & 5,214 & 1,025 & $-0,061$ & 1,055 \\
\hline 26,43 & 698,41 & 664,27 & $-5,139$ & 31,37 & 30,08 & $-4,290$ & 0,87 & $-0,42$ & 1,043 & 1,097 & 4,888 & 1,025 & $-0,482$ & 1,051 \\
\hline 16,71 & 549,17 & 497,25 & $-10,441$ & 37,42 & 33,81 & $-10,695$ & 6,92 & 3,31 & 1,327 & 1,465 & 9,454 & 1,050 & 0,478 & 1,104 \\
\hline 18,71 & 589,60 & 534,48 & $-10,314$ & 35,84 & 32,52 & $-10,216$ & 5,34 & 2,02 & 1,236 & 1,363 & 9,349 & 1,050 & 0,378 & 1,103 \\
\hline 20,31 & 616,76 & 559,50 & $-10,235$ & 34,67 & 31,58 & $-9,786$ & 4,17 & 1,08 & 1,181 & 1,302 & 9,285 & 1,050 & 0,258 & 1,102 \\
\hline 23,30 & 661,46 & 600,91 & $-10,077$ & 32,81 & 30,20 & $-8,641$ & 2,31 & $-0,30$ & 1,101 & 1,212 & 9,154 & 1,050 & $-0,130$ & 1,101 \\
\hline 24,14 & 672,09 & 611,15 & $-9,971$ & 32,39 & 29,90 & $-8,328$ & 1,89 & $-0,60$ & 1,084 & 1,192 & 9,067 & 1,050 & $-0,316$ & 1,100 \\
\hline 25,23 & 684,79 & 617,22 & $-10,947$ & 31,85 & 29,35 & $-8,518$ & 1,35 & $-1,15$ & 1,064 & 1,180 & 9,867 & 1,050 & $-0,847$ & 1,109 \\
\hline 26,43 & 698,41 & 635,29 & $-9,936$ & 31,37 & 29,24 & $-7,298$ & 0,87 & $-1,26$ & 1,043 & 1,147 & 9,038 & 1,050 & $-1,450$ & 1,099 \\
\hline 16,71 & 549,17 & 476,63 & $-15,218$ & 37,42 & 32,47 & $-15,239$ & 6,92 & 1,97 & 1,327 & 1,529 & 13,208 & 1,075 & 0,285 & 1,152 \\
\hline 18,71 & 589,60 & 510,52 & $-15,490$ & 35,84 & 31,23 & $-14,779$ & 5,34 & 0,73 & 1,236 & 1,427 & 13,412 & 1,075 & 0,136 & 1,155 \\
\hline 20,31 & 616,76 & 534,98 & $-15,287$ & 34,67 & 30,37 & $-14,138$ & 4,17 & $-0,13$ & 1,181 & 1,362 & 13,260 & 1,075 & $-0,031$ & 1,153 \\
\hline 23,30 & 661,46 & 575,64 & $-14,909$ & 32,81 & 29,21 & $-12,323$ & 2,31 & $-1,29$ & 1,101 & 1,266 & 12,974 & 1,075 & $-0,558$ & 1,149 \\
\hline 24,14 & 672,09 & 583,70 & $-15,142$ & 32,39 & 28,95 & $-11,879$ & 1,89 & $-1,55$ & 1,084 & 1,248 & 13,151 & 1,075 & $-0,818$ & 1,151 \\
\hline 25,23 & 684,79 & 593,58 & $-15,366$ & 31,85 & 28,55 & $-11,584$ & 1,35 & $-1,95$ & 1,064 & 1,227 & 13,319 & 1,075 & $-1,442$ & 1,154 \\
\hline 26,43 & 698,41 & 611,56 & $-14,201$ & 31,37 & 28,58 & $-9,759$ & 0,87 & $-1,92$ & 1,043 & 1,191 & 12,435 & 1,075 & $-2,203$ & 1,142 \\
\hline 16,71 & 549,17 & 494,19 & $-11,124$ & 37,42 & 33,44 & $-11,899$ & 6,92 & 2,94 & 1,327 & 1,474 & 10,011 & 1,100 & 0,425 & 1,111 \\
\hline 18,71 & 589,60 & 494,41 & $-19,255$ & 35,84 & 30,38 & $-17,989$ & 5,34 & $-0,12$ & 1,236 & 1,474 & 16,146 & 1,100 & $-0,023$ & 1,193 \\
\hline 20,31 & 616,76 & 513,30 & $-20,156$ & 34,67 & 29,41 & $-17,877$ & 4,17 & $-1,09$ & 1,181 & 1,419 & 16,775 & 1,100 & $-0,262$ & 1,202 \\
\hline 23,30 & 661,46 & 552,94 & $-19,625$ & 32,81 & 28,36 & $-15,679$ & 2,31 & $-2,14$ & 1,101 & 1,318 & 16,406 & 1,100 & $-0,925$ & 1,196 \\
\hline 24,14 & 672,09 & 563,40 & $-19,291$ & 32,39 & 28,17 & $-14,969$ & 1,89 & $-2,33$ & 1,084 & 1,293 & 16,171 & 1,100 & $-1,229$ & 1,193 \\
\hline 25,23 & 684,79 & 574,27 & $-19,245$ & 31,85 & 27,95 & $-13,954$ & 1,35 & $-2,55$ & 1,064 & 1,269 & 16,139 & 1,100 & $-1,881$ & 1,192 \\
\hline 26,43 & 698,41 & 592,53 & $-17,868$ & 31,37 & 27,97 & $-12,169$ & 0,871 & $-2,5326$ & 1,043 & 1,230 & 15,160 & 1,100 & $-2,908$ & 1,179 \\
\hline
\end{tabular}


Форма и размеры овального калибра, а также задаваемой в него круглой заготовки, представлены на рис. 2. Форма и размеры калибра выбирались исходя из условий экспериментальных исследований.

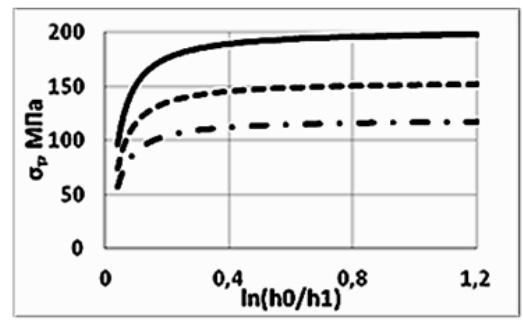

a

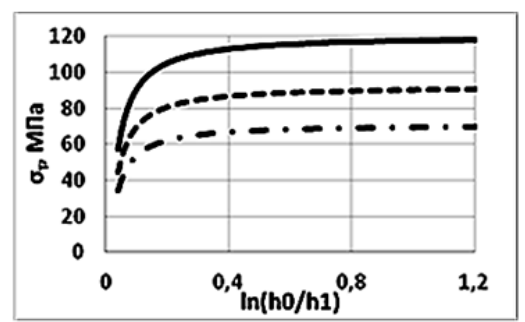

6

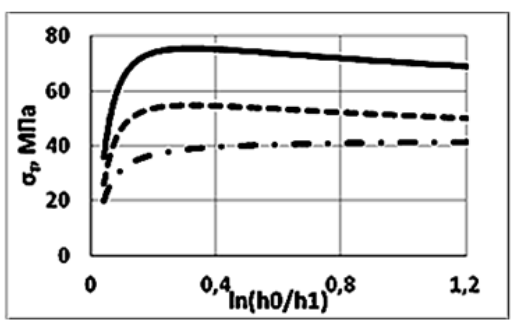

B

Рис. 1. Реологические зависимости стали 08X13:

a-температура деформации $800{ }^{\circ} \mathrm{C} ; \quad$ б-температура деформации $1000{ }^{\circ} \mathrm{C}$; в - температура деформации $1200{ }^{\circ} \mathrm{C}$; $\varepsilon$ : — - 10 -1с; $\varepsilon$ : - - - 1 -1c; $\varepsilon:$ - • - - 0,1 -1c

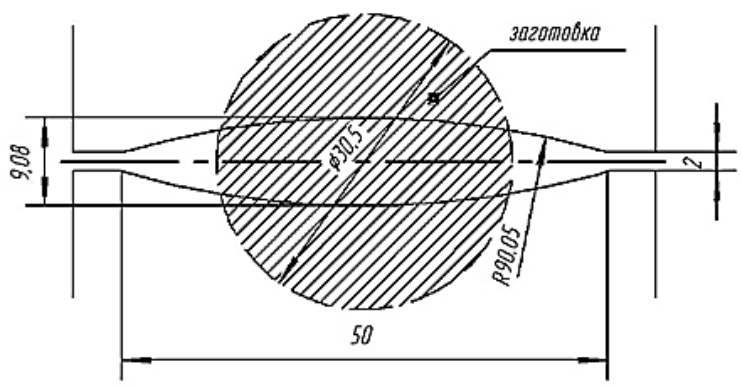

Рис. 2. Овальный калибр и задаваемый в него профиль

Система «овал - круг» рассмотрена на примере схемы «круг-овал» при прокатке круглой заготовки в овальном калибре. Моделирование по указанной схеме выполнялось для случаев прокатки с различными сочетаниями переднего и заднего натяжения. Исследования проводились для условий рассогласования скоростей переднего, заднего, одновременно переднего и заднего концов полосы. Диапазон относительного рассогласования скоростей (по отношению к прокатке без натяжения) составил 2,5...10 \% с кратностью 2,5.

Диапазон изменения коэффициентов вытяжки составил $\lambda=1,043 \ldots 1,529$, он является достаточно характерным для данной системы калибров.

Установлено, что при малых значениях коэффициента вытяжки и значительном рассогласовании скоростей в условиях одновременного действия переднего и заднего натяжения в исследованных системах калибров может происходить утяжка профиля (возникает отрицательное уширение).

Полученные данные носят информационный характер и могут быть использованы для проектирования и разработки режима деформации при прокатке специальных сталей и сталей, склонных к повышенному уширению, в системе калибров «овал-круг».

\section{ВЫВОДЫ}

Выполнено моделирование процесса прокатки круглой заготовки в овальном калибре. Исследованы изменения деформационных и кинематических параметров непрерывной прокатки в зависимости от варьируемых параметров. Выявлены закономерности изменения параметров прокатки во взаимосвязи друг с другом. Выявлен качественный и количественный (для исследованного диапазона параметров) характер изменения параметров прокатки в зависимости от натяжения (рассогласования скоростей). Предварительное сравнение результатов моделирования и экспериментальных данных позволяет сделать вывод о достаточной их сходимости и возможности использования программы FORGE 3D для решения практических задач, связанных с прокаткой в системе калибров «овал-круг». 


\section{СПИСОК ИСПОЛЬЗОВАННОЙ ЛИТЕРАТУРЫ}

1. Dyja H. Using software product FORGE3 for researching of the special steel broadening/ H. Dyja, O. Remez, S. Mroz, A. Samsonenko // Hutnik. Collection of science papers. - 2010. - № 5. - P. $225-227$.

2. Данченко В. Н. Теоретическое исследование изменения ширины профиля при прокатке специальных сталей в калибрах простой формы с использованием программного продукта FORGE3 / B. Н. Данченко, O. А. Ремез, Sebastian Mroz, А. А. Самсоненко // Обработка материалов давлением : сб. науч. трудов. - Краматорск : ДГМА, 2010. - № 1(22). - С. 210-217.

3. Mroz S. Investigation of wear of roughing stand's rolls of the section mill at rolling of crane rails / S. Mroz, O. Remez, V. Andreiev, A. Samsonenko, M. Kraev, O. Kuzmina // HUTNIK. WIADOMOSCI HUTNICZE. - Tom LXXIX. № 5. $-2012-P$. 349-352.

4. Миленин А. А. Проблемы разработки и применения трехмерных численных моделей для оптимизации прочессов прокатки / А. А. Миленин // Наукові вісті : Сучасні проблеми металургї. - 2002. - T. 5. - № 3. - С. 36-46.

5. Modelowanie procesow kucia swobodnego: seria "Metalurgia" / [H.S.Dyja, G. A. Banaszek, V. A. Grynkevych, V. N. Danchenko]. - Czestochowa, 2004. - Nr $42-355$ s.

6. Strain and stress analysis in forward extrusion process of bimetallic rods / Berski S., Dyja H., Milenin A. [ma ін.] // Наукові вісті : Сучасні проблеми металургї. Пластична деформачія металів. - 2002. - T. 5. - С. $250-254$.

7. Миленин А. А. Разработка научных основ и развитие технологий трехмерного пластического формоизменения металлов с применением методов компьютерного моделирования: диссертация на соискание ученой степени доктора технических наук : 05.03.05 / Андрей Анатольевич Миленин. - Днепропетровск, 2001. - 320 с.

8. Ершов С. В. Развитие теории напряженно-деформированного состояния металла при прокатке крупных круглых профилей с пониженным трещчинооразованием в системе сортовых калибров: диссертация на соискание ученой степени доктора технических наук : 05.03.05 / Ершов Сергей Владимирович. - Днепродзержинск, 2008. - 301 с.

9. Вызрин В. Н. Процесс непрерывной прокатки / В. Н. Выдрин, А. С. Федосиенко, В. И. Крайнов. - М. : Металлургия, 1970. - 456 с.

10. Онищенко И. И. Теория непрерывной прокатки / И. И. Онищченко, П. И. Куцченко, А. И. Куцеенко. Запорожье : Изд-во ЗГИА, $1998-470$ с.

11. Непрерывная прокатка : кол. монограф. под ред. д-ра техн. наук, проф. В. Н. Данченко. - Дніпропетровськ : РВА «Дніпро-ВАЛ», 2002. - 588 с. - ISBN 966-7616-40-1.

12. Чекмарев А. П. Межклетевое натяжение при непрерывной прокатке / А. П. Чекмарев, И. А. Чекмарев, А. Я. Семенюта // Обработка металлов давлением : сборник научных трудов ДМетИ. - М. : Металлургия, 1970. - № 55. - C. 5-7.

13. Предельные значения динамического и кинематического натяжения при непрерывной прокатке / А. П. Чекмарев, В. И. Прокофьев, А. А. Динник [и др.] // Обработка металлов давлением : сборник научных трудов ДМетИ. - М. : Металлургия, 1970. - № 55. - С. 7-14.

14. Чекмарев А. П. Деформация полосы в межклетевом пространстве при непрерывной прокатке с натяжением / А. П. Чекмарев, И. И. Онищенко // Обработка металлов давлением : сборник научных трудов ДМетИ. - М. : Металлургия, 1965. - № 49. - С. 24-40.

15. Комплексное исследование процесса непрерывной прокатки / [А. П. Чекмарев, И. И. Онищенко, В. В. Гетманеи, М. П. Топоровский] // Обработка металлов давлением : сборник научных трудов ДМетИ. - М. : Металлургия, 1965. - № 49. - С. 41-73.

16. Мутьев М. С. Исследование процесса прокатки с натяжением / М. С. Мутьев, Л. Н. Левченко, Л. Ф. Машкин // Обработка металлов давлением : сборник научных трудов ДМетИ. - М. : Металлургия, 1965. - № 49. - С. $73-87$.

17. Динник А. А. Исследование межклетевой деформации полосы на непрерывном проволочном стане / А. А. Динник, Л. Б. Черногоров, А. Н. Комаров // Обработка металлов давлением: сборник научньх трудов ДМетИ. - М. : Металлургия, 1965. - № 49. - С. 104-110.

18. К вопросу определения межклетевых деформаций при горячей прокатке на непрерывных станах / [В. И. Тарновский, А. А. Поздеев, В. И. Еремеев, А. Г. Криволапов] // Сборник научных трудов. - Челябинск : Челябинский политехнический институт, 1968. - № 54. - С. 29-39.

19. Хензель А. Расчет энергосиловых параметров в процессах обработки металлов давлением / А. Хензель, Т. Шпиттель. - М. : Металлургия, 1982. - 360 с.

20. Полухин П. И. Сопротивление пластической деформации металлов и сплавов / П. И. Полухин, Г. Я. Гун, А. М. Галкин. - М. : Металлургия, 1976. - 488 с.

\section{REFERENCES}

1. Dyja H. Using software product FORGE3 for researching of the special steel broadening/ H. Dyja, O. Remez, S. Mroz, A. Samsonenko // Hutnik. Collection of science papers. - 2010. - № 5. — P. $225-227$.

2. Danchenko V. N. Teoreticheskoe issledovanie izmenenija shiriny profilja pri prokatke special'nyh stalej $v$ kalibrah prostoj formy s ispol'zovaniem programmnogo produkta FORGE3 / V. N. Danchenko, O. A. Remez, Sebastian Mroz, A. A. Samsonenko // Obrabotka materialov davleniem : sb. nauch. trudov. - Kramatorsk : DGMA, 2010. № 1(22). - S. 210-217. 
3. Mroz S. Investigation of wear of roughing stand's rolls of the section mill at rolling of crane rails / S. Mroz, O. Remez, V. Andreiev, A. Samsonenko, M. Kraev, O. Kuzmina // HUTNIK. WIADOMOSCI HUTNICZE. - Tom LXXIX. № 5. $-2012-$ P. 349-352.

4. Milenin A. A. Problemy razrabotki i primenenija trehmernyh chislennyh modelej dlja optimizacii processov prokatki / A. A. Milenin // Naukovi visti : Suchasni problemi metalurgii. - 2002. - T. 5. - № 3. - S. 36-46.

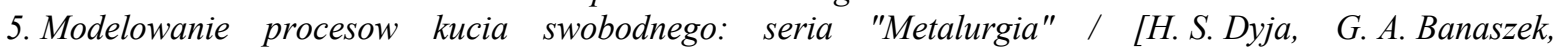
V. A. Grynkevych, V. N. Danchenko]. - Czestochowa, 2004. - Nr $42-355$ s.

6. Strain and stress analysis in forward extrusion process of bimetallic rods / Berski S., Dyja H., Milenin A. [ta in.] // Naukovi visti : Suchasni problemi metalurgiï. Plastichna deformacija metaliv. - 2002. - T. 5. - S. 250-254.

7. Milenin A. A. Razrabotka nauchnyh osnov i razvitie tehnologij trehmernogo plasticheskogo formoizmenenija metallov s primeneniem metodov komp'juternogo modelirovanija: dissertacija na soiskanie uchenoj stepeni doktora tehnicheskih nauk : 05.03.05 / Andrej Anatol'evich Milenin. - Dnepropetrovsk, 2001. - 320 s.

8. Ershov S. V. Razvitie teorii naprjazhenno-deformirovannogo sostojanija metalla pri prokatke krupnyh kruglyh profilej s ponizhennym treshhinoobrazovaniem $v$ sisteme sortovyh kalibrov: dissertacija na soiskanie uchenoj stepeni doktora tehnicheskih nauk: 05.03.05 / Ershov Sergej Vladimirovich. - Dneprodzerzhinsk, 2008. - 301 c.

9. Vydrin V. N. Process nepreryvnoj prokatki /V. N. Vydrin, A. S. Fedosienko, V. I. Krajnov. - M. : Metallurgija, 1970. $-456 \mathrm{~s}$

10. Onishhenko I. I. Teorija nepreryvnoj prokatki / I. I. Onishhenko, P. I. Kucenko, A. I. Kucenko. - Zaporozh'e : Izd-vo ZGIA, $1998-470 \mathrm{~s}$.

11. Nepreryvnaja prokatka : kol. monograf. pod red. d-ra tehn. nauk, prof. V. N. Danchenko. - Dnipropetrovs'k : RVA «Dnipro-VAL», 2002. - 588 s. - ISBN 966-7616-40-1.

12. Chekmarev A. P. Mezhkletevoe natjazhenie pri nepreryvnoj prokatke / A. P. Chekmarev, I. A. Chekmarev, A. Ja. Semenjuta // Obrabotka metallov davleniem : sbornik nauchnyh trudov DMetI. - M. : Metallurgija, 1970. № $55 .-$ S. 5-7.

13. Predel'nye znachenija dinamicheskogo i kinematicheskogo natjazhenija pri nepreryvnoj prokatke / A. P. Chekmarev, V. I. Prokof'ev, A. A. Dinnik [i dr.] // Obrabotka metallov davleniem : sbornik nauchnyh trudov DMetI. - M. : Metallurgija, 1970. - № 55. - S. 7-14.

14. Chekmarev A. P. Deformacija polosy v mezhkletevom prostranstve pri nepreryvnoj prokatke $s$ natjazheniem / A. P. Chekmarev, I. I. Onishhenko // Obrabotka metallov davleniem : sbornik nauchnyh trudov DMetI. M. : Metallurgija, 1965. - № 49. - S. 24-40.

15. Kompleksnoe issledovanie processa nepreryvnoj prokatki / [A. P. Chekmarev, I. I. Onishhenko, V. V. Getmanec, M. P. Toporovskij] // Obrabotka metallov davleniem : sbornik nauchnyh trudov DMetI. - M. : Metallurgija, 1965. - № 49. - S. 41-73.

16. Mut'ev M. S. Issledovanie processa prokatki s natjazheniem / M. S. Mut'ev, L. N. Levchenko, L. F. Mashkin // Obrabotka metallov davleniem : sbornik nauchnyh trudov DMetI. - M. : Metallurgija, 1965. - № 49. - S. $73-87$.

17. Dinnik A. A. Issledovanie mezhkletevoj deformacii polosy na nepreryvnom provolochnom stane / A. A. Dinnik, L. B. Chernogorov, A. N. Komarov // Obrabotka metallov davleniem: sbornik nauchnyh trudov DMetI. M. : Metallurgija, 1965. - № 49. - S. 104-110.

18. K voprosu opredelenija mezhkletevyh deformacij pri gorjachej prokatke na nepreryvnyh stanah / [V. I. Tarnovskij, A. A. Pozdeev, V. I. Eremeev, A. G. Krivolapov] // Sbornik nauchnyh trudov. - Cheljabinsk : Cheljabinskij politehnicheskij institut, 1968. - № 54. - S. 29-39.

19. Henzel' A. Raschet jenergosilovyh parametrov v processah obrabotki metallov davleniem / A. Henzel', T. Shpittel'. - M. : Metallurgija, 1982. - 360 s.

20. Poluhin P. I. Soprotivlenie plasticheskoj deformacii metallov i splavov / P. I. Poluhin, G. Ja. Gun, A. M. Galkin. - M. : Metallurgija, 1976. - 488 s.

Ремез О. А. - канд. техн. наук, доц. каф. ОМД НМетАУ;

Огинский И. К. - д-р техн. наук, зав. каф. МО ЗГИА;

Кузьмина О. М. - канд. техн. наук, доц. каф. ОМД НМетАУ.

ЗГИА - Запорожская государственная инженерная академия, г. Запорожье.

НМетАУ - Национальная металлургическая академия Украины, г. Днепр.

E-mail: remez@metal-forming.org 